\title{
Isolation and Screening of Indigenous Plant Growth-promoting Rhizobacteria from Different Rice Cultivars in Afghanistan Soils
}

\author{
Safiullah Habibi ${ }^{1}$, Salem Djedidi ${ }^{2}$, Naoko Ohkama-Ohtsu ${ }^{2}$, Wakil Ahmad Sarhadi ${ }^{1}$, Katsuhiro Kojima ${ }^{2}$, \\ Roland V. Rallos ${ }^{3}$, Maria Daniela Artigas Ramirez ${ }^{2}$, Hiroko Yamaya ${ }^{2}$, Hitoshi Sekimoto ${ }^{4}$, \\ and TADASHI YOKOYAMA ${ }^{2 *}$ \\ ${ }^{1}$ Faculty of Agriculture, Kabul University, Afghanistan; ${ }^{2}$ Institute of Agriculture, Tokyo University of Agriculture and Technology, \\ Japan; ${ }^{3}$ Nuclear Research Institute, 1101 Quezon, Philippines; and ${ }^{4}$ Faculty of Agriculture, Utsunomiya University, Japan
}

(Received December 30, 2018 -Accepted April 27, 2019-Published online September 14, 2019)

To develop biofertilizers for rice in Afghanistan, 98 plant growth-promoting rhizobacteria were isolated from rice plants and their morphological and physiological characteristics, such as indole-3-acetic acid production, acetylene reduction, phosphate and potassium solubilization, and siderophore production, were evaluated. The genetic diversity of these bacteria was also analyzed based on $16 \mathrm{~S}$ rRNA gene sequences. Of 98 bacteria, 89.7\% produced IAA, 54.0\% exhibited nitrogenase activity, and $40 \%$ showed phosphate solubilization and siderophore production. Some isolates assigned to Pseudomonas (brassicacearum, chengduensis, plecoglossicida, resinovorans, and straminea) formed a relationship with rice, and $P$. resinovorans and $P$. straminea showed nitrogen fixation. Rhizobium borbori and $R$. rosettiformans showed a relationship with rice plants and nitrogen fixation. Among the isolates examined, AF134 and AF137 belonging to Enterobacter ludwigii and P. putida produced large amounts of IAA $\left(92.3 \mu \mathrm{g} \mathrm{mL}^{-1}\right)$ and exhibited high nitrogenase activity $\left(647.4 \mathrm{nmol} \mathrm{C}_{2} \mathrm{H}_{4} \mathrm{~h}^{-1}\right)$, respectively. In the plant growth test, more than $70 \%$ of the inoculated isolates showed significantly increased root and shoot dry weights. Highly diverse bacterial isolates showing promising rice growth-promoting traits were obtained from Afghanistan alkaline soils.

Key words: rice, PGPR, IAA, ARA, phosphate and potassium solubilization, 16S rRNA

Rice is one of the most important staple foods for more than half of the world's population (20), and accounts for $23 \%$ of the world's calorie intake (6). Nitrogen $(N)$ is one of the main limiting nutrients for crop productivity, including rice (27), and only one-third of the $\mathrm{N}$ applied as chemical fertilizer is used by rice plants (3). Phosphorus (P) and potassium (K) are major essential macronutrients for plants and are applied to soil in the form of phosphatic and potash fertilizers. However, a large portion of soluble inorganic $\mathrm{P}$ applied to soil as a chemical fertilizer is rapidly immobilized and becomes unavailable for plants (38).

Plant growth-promoting rhizobacteria (PGPR) were initially defined by Kloepper and Schroth (23) as a group of bacteria that colonize plant roots and exert beneficial effects on plant growth. They promote plant growth through direct and indirect mechanisms. Direct mechanisms are nitrogen fixation (4), the solubilization of nutrients, such as $\mathrm{P}(10)$ and $\mathrm{K}(21)$, siderophore production (25), phytohormone production $(15,39)$, and increasing crop tolerance to abiotic stress by producing chemical compounds, including enzymes (ACC-deaminase and chitinase), and substances, such as exopolysaccharides and rhizobitoxine (34). The indirect effects of PGPR on growth promotion

\footnotetext{
* Corresponding author. E-mail: tadashiy@cc.tuat.ac.jp;

Tel: +81-42-367-5878; Fax: +81-42-367-5878.

Abbreviations: ARA, Acetylene reduction assay; BLAST, Basic local alignment search tool; CTAB, Hexadecyltrimethylammonium bromide; DDBJ, DNA data bank Japan; DNA, Deoxyribonucleic acid; FFTC, Food and fertilizer technology center; IAA, Indole-3acetic acid; MEGA, Molecular Evolutionary Genetics Analysis; PCR, Polymerase chain reaction; PGP, Plant growth-promoting; PGPR, Plant growth-promoting rhizobacteria
}

occur against plant pathogens through several mechanisms, including induced systemic resistance (ISR), the production of antimicrobial compounds, and competition with pathogens for nutrients and colonization sites $(11,24)$.

PGPR have been extensively examined in an attempt to discover the most promising inoculants and develop biofertilizers and biocontrol agents (40) for various crops. Thus, many PGPR strains have been commercialized to promote plant growth (16). In many Asian countries, bio-fertilizer and biopesticide technologies are now in various stages of development and utilization $(14,36)$.

Rice is one of the most important staple crops in Afghanistan. It is widely grown in the North Eastern provinces. Large amounts of chemical fertilizers are required to obtain appropriate rice yields. Due to the environmental issues associated with the application of chemical fertilizers, the development of PGPR biofertilizers may be an effective and eco-friendly approach to reduce the use of chemical fertilizers and promote plant growth. Rice-associated PGPR have not yet been examined in Afghanistan soils, and, thus, the present study is the first to investigate rice-associated PGPR and develop biofertilizers for rice in Afghanistan.

\section{Materials and Methods}

\section{Soil sampling}

Fifteen soil samples from different ecological zones and various fields (rice and legumes) in Afghanistan were collected at a depth of 0-20 cm (Fig. 1) and used to isolate PGPR. Thirteen soil samples belonged to paddy fields (rice rhizosphere) and two soil samples to upland fields (alfalfa and clover). These soil samples were used as inoculants to 5 rice cultivars. 


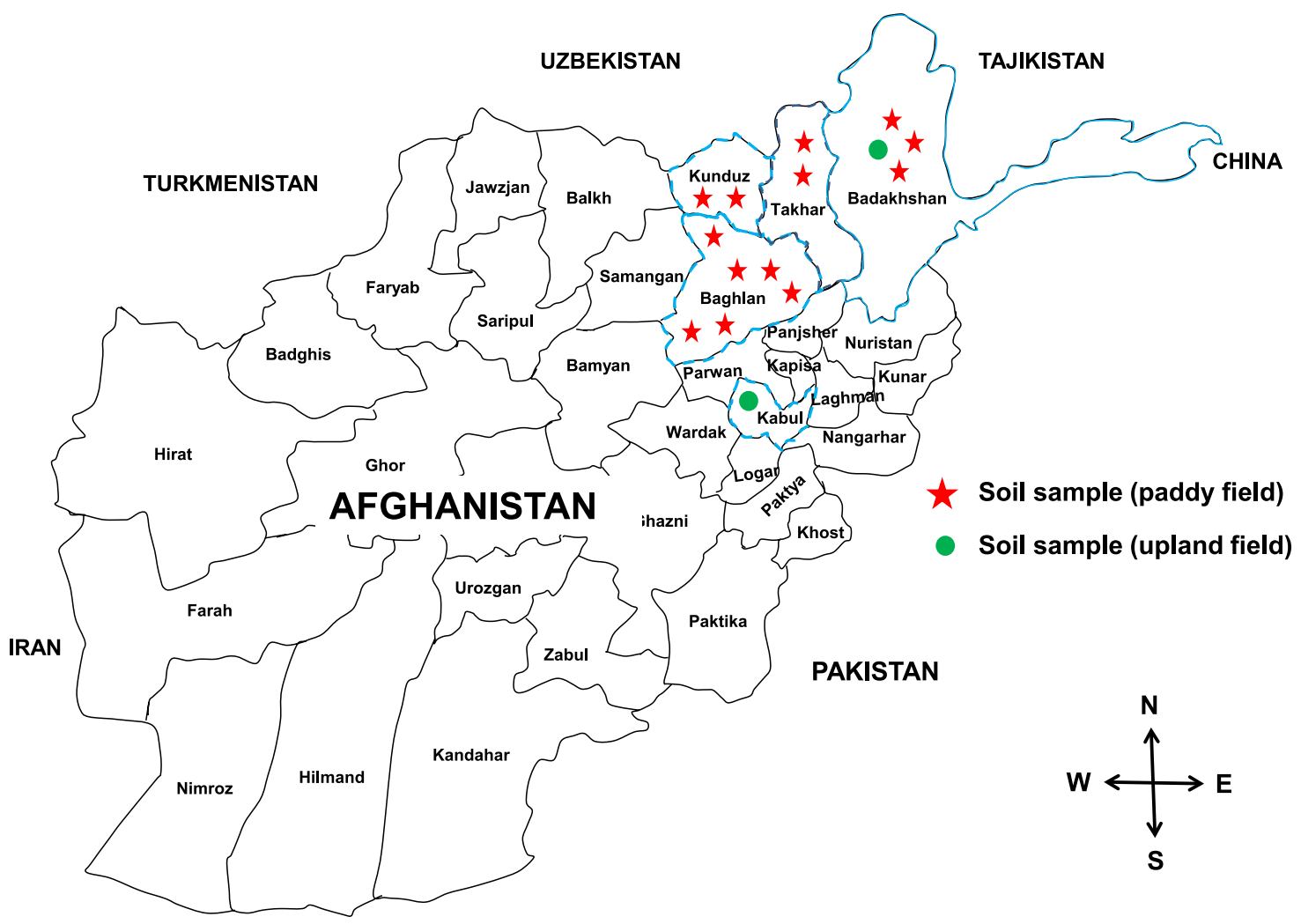

Fig. 1. Map of Afghanistan showing soil sample collection sites.

\section{Isolation of PGPR}

Regarding the isolation of PGPR, we followed the method described by Habibi et al. (19). The seeds of 5 rice cultivars (One Japanese [cv. Leaf star] and 4 Afghan [cv. Bala Doshi; cv. Monda Laghman; cv. Look Andarab and cv. Sorkhaq]) were surface-sterilized in $70 \%$ ethanol for $30 \mathrm{~s}$, and in 3\% sodium hypochlorite for $3 \mathrm{~min}$. Twenty grams of soil from each soil sample was used as an inoculant to seeds in a pot containing sterilized vermiculite. Pots were kept in a growth chamber under controlled conditions (16-h light $\left[250 \mu \mathrm{mol} \mathrm{m}{ }^{-2} \mathrm{~s}^{-1}\right] / 8$ - $\mathrm{h}$ dark photoperiod, at $25^{\circ} \mathrm{C} / 18^{\circ} \mathrm{C}$ day/night temperatures). After 3 weeks, all plants were harvested, and 98 bacterial strains from the roots and leaves of rice plants were isolated using $\mathrm{NFb}$ semi-solid medium (12).

\section{Indole-3-acetic acid (IAA) production of isolates}

In the IAA evaluation, $\mathrm{NFb}$ broth containing $100 \mathrm{mg} \mathrm{L}^{-1}$ L-tryptophan was inoculated by each strain, and incubated at $28^{\circ} \mathrm{C}$ for $2 \mathrm{~d}$ in the dark. Cell suspensions were then centrifuged at $9,730 \times g$ for $15 \mathrm{~min}$ to remove cells, and the concentration of IAA in the supernatant was measured using the Salkovski colorimetric technique (17) by measuring absorbance at $530 \mathrm{~nm}$ with a spectrophotometer (Ultrospec 3300 pro; Amersham Biosciences, Cambridge, United Kingdom). Cell density was assessed by the plate dilution method.

\section{Acetylene reduction assay (ARA) of isolates}

In ARA, bacterial cultures were grown in vials containing $\mathrm{N}$-free semisolid $\mathrm{NFb}$ medium and incubated at $28^{\circ} \mathrm{C}$ for $2 \mathrm{~d}$. A total of $10 \%$ acetylene $(\mathrm{v} / \mathrm{v})$ was then injected into each vial and the cultures were further incubated at $30^{\circ} \mathrm{C}$ for $1 \mathrm{~h}$. The concentration of ethylene in the vials was assessed using a Shimadzu 2014AF gas chromatograph (Shimadzu, Kyoto, Japan). Un-inoculated tubes were used as a negative control. The number of cells in each vial was measured by the plate dilution method.

\section{$P$ - and $K$-solubilizing activities of isolates}

Bacterial isolates were grown in NFb broth medium at $28^{\circ} \mathrm{C}$ for $48 \mathrm{~h}$. Five microliters $\left(10^{6}\right.$ cells $\left.\mathrm{mL}^{-1}\right)$ of each culture was spotted onto Pikovskaia's medium containing tricalcium phosphate (37) and slightly modified Aleksandrov medium (21). Plates were incubated at $28^{\circ} \mathrm{C}$ for $7 \mathrm{~d}$. The P- and $\mathrm{K}$-solubilizing activities (formation of a halozone or clear zone around bacterial colonies) of each isolate were evaluated by measuring the size of the halozone.

\section{Siderophore production by isolates}

Bacterial isolates were grown in $\mathrm{NFb}$ broth medium at $28^{\circ} \mathrm{C}$ for $48 \mathrm{~h}$. Five microliters $\left(10^{6}\right.$ cells $\left.\mathrm{mL}^{-1}\right)$ of each culture was spotted onto Chrome-azurol S (CAS) medium (2). Plates were incubated at $28^{\circ} \mathrm{C}$ for $2 \mathrm{~d}$. The siderophore-solubilizing activity (formation of an orange or yellow halozone around colonies) of each isolate was evaluated by measuring the size of the orange or yellow zone around the colony.

\section{Molecular characterization}

To assess genetic diversity, 81 (82.6\% of the total) isolates were selected based on their physiological properties, host rice varieties, and climatic regions. These isolates were grown in NFb broth medium at $25^{\circ} \mathrm{C}$ for $4 \mathrm{~d}$. Prior to genomic isolation, cells were harvested and washed twice with equal volumes of TNE buffer $(10 \mathrm{mM}$ Tris, $0.1 \mathrm{M} \mathrm{NaCl}$, and $1 \mathrm{mM}$ EDTA, $\mathrm{pH}$ 8). Genomic DNA was extracted from isolates using the method described by Yokoyama et al. (44). DNA concentrations and purities were examined using a NanoDrop 2000 UV-Vis spectrophotometer (Thermo Fisher Scientific, Wilmington, DE, USA).

\section{DNA amplification and sequencing}

PCR amplification and sequencing of the 16S rRNA gene were conducted as described previously (19). The bacterial universal primers $27 f$ (5'-AGTTTGATCCTGGCTC-3') and 1525r (5'-AAG 
GAGGTGATCCAGCC-3') were used to sequence the 16S rRNA gene. Amplifications were performed using $50-\mu \mathrm{L}$ reaction mixtures containing $2 \mu \mathrm{M}$ of the primer set $27 \mathrm{f}$ and $1525 \mathrm{r}, 0.5 \mu \mathrm{L}$ Taq DNA Polymerase (ExTaq polymerase $5 \mathrm{U} \mathrm{mL}^{-1}$, Takara Bio, Otsu, Japan), $5 \mu \mathrm{L} 10 \times$ reaction buffer, $4 \mu \mathrm{L}$ dNTP mixture, and $1 \mu \mathrm{L}$ DNA template (200-250 ng DNA). PCR products were checked by electrophoresis on a $1.5(\mathrm{w} / \mathrm{v})$ agarose gel. Amplified DNA bands corresponding to the 16S rRNA gene were purified using a QIAEX II agarose gel extraction kit (Qiagen, Valencia, CA, USA). Amplified DNA bands corresponding to the 16S rRNA gene were purified using a QIAEX II agarose gel extraction kit (Qiagen). Purified products were reacted using an ABI Prism BigDye Terminator v 3.1 cycle sequencing kit (Applied Biosystems, Foster City, CA, USA) and 27F and 1525r primers. Sequencing reaction mixtures were then analyzed using an ABI PRISM 3500 genetic analyzer (Applied Biosystems) according to the manufacturer's protocols to obtain the DNA sequence of the $16 \mathrm{~S}$ rRNA gene. Sequenced data were compared using the online software BLAST. Sequence alignment and construction of the phylogenetic tree were performed using MEGA version 6.06 (41).

\section{Effects of PGPR on rice growth}

Based on physiological characteristics and sampling sites, 24 isolates were selected to evaluate their effects on rice growth. We used one Afghan rice cultivar (Bala Doshi) to evaluate the growth potential of selected isolates. Prior to sowing, 37 isolates were grown in $20 \mathrm{~mL}$ of $\mathrm{NFb}$ broth medium at $28^{\circ} \mathrm{C}$ for $2 \mathrm{~d}$. The seeds of one Afghan rice cultivar (cv. Bala Doshi) were surface-sterilized as described in the PGPR isolation section. Germinated seeds were transplanted into pots containing gamma-irradiated (3 replicates) paddy field soil (185 g) (19), and each bacterial culture at a cell density of $10^{9}$ colony forming units $\mathrm{mL}^{-1}(\mathrm{CFU} \mathrm{mL}-1)$ was then applied to the seeds in the pot. All pots were transferred to a growth chamber controlled at $28^{\circ} \mathrm{C} \pm 2^{\circ} \mathrm{C}$ during the day $(16 \mathrm{~h})$ and $25^{\circ} \mathrm{C} \pm 2^{\circ} \mathrm{C}$ during the night $(8 \mathrm{~h})$. Each pot was irrigated with sterilized distilled water. Un-inoculated plants (negative control) and those inoculated with 2 strains: Azosperillum brasilense (Ts-13) (31) and Bacillus pumilus (TUAT-1), were used as positive controls. Plants were harvested after 3 weeks. The fresh weights of roots and shoots were recorded, and roots and shoots were then dried at $60^{\circ} \mathrm{C}$ for $2 \mathrm{~d}$ before dry weight measurements. The significance of differences between treatments and controls was analyzed using Tukey's test $(P<0.05)$

\section{Results}

\section{Isolation of PGPR}

In the present study, the morphological characteristics of isolates were examined to evaluate colony diversity. The physiological characteristics of isolates were considered to differ more among the various colonies. Thus, based on the morphological characteristics of isolates, such as the form (circular, filamentous, and irregular), color (white, whitish, yellow, yellowish, creamy, and transplant), elevation (convex, flat, raised, crateriform, and umbonate), and margins (entire, filiform, and undulate) of colonies, 98 bacteria were selected and used in subsequent experiments. Soil samples and the number of isolates related to each province are shown in Table 1.

\section{Physiological properties of isolates}

In the present study, some important physiological properties of PGPR, such as IAA production, nitrogen fixation, P solubilization, and $\mathrm{K}$ solubilization, were evaluated for some isolates (Table 2).

Among 98 isolates, $89.7 \%$ produced IAA, ranging between 2.0 and $92.3 \mu \mathrm{g} \mathrm{mL}^{-1}$. The frequencies of isolates related to each rice cultivar with the ability to produce IAA are shown in Fig. 2. Among all isolates, the AF134 isolate obtained from the leaves of Monda Laghman showed maximum IAA production $(92.3 \mu \mathrm{g} \mathrm{mL}-1)$ followed by the AF135 $\left(74.93 \mu \mathrm{gL}^{-1}\right)$ isolate obtained from the roots of Sorkhaq (Table 2). Isolates obtained from Look-Andarab showed the highest frequency of IAA producers (100\%) among the 5 rice varieties (Fig. 2).

Among 98 isolates, $54 \%$ exhibited ARA. Ethylene production rates varied widely among the isolates, and fluctuated between 0.1 and $647.4 \mathrm{nmol} \mathrm{C}_{2} \mathrm{H}_{4} \mathrm{~h}^{-1} 10^{-6}$ cells (Table 2). Bala Doshi isolates had a higher frequency of nitrogen-fixing bacteria $(60.7 \%)$ than the 4 other rice cultivar isolates (Fig. 2). The AF137 isolate obtained from the leaves of Sorkhaq exhibited the highest nitrogenase activity (647.4 nmol $\mathrm{C}_{2} \mathrm{H}_{4} \mathrm{~h}^{-1} 10^{-6}$ ) among all isolates (Table 2). Similarly, the $\mathrm{AF} 84, \mathrm{AF} 51, \mathrm{AF} 30, \mathrm{AF} 75$, and AF124 isolates exhibited higher ARA activity than the other isolates. These isolates were categorized as $R$. daejeonense.

The $\mathrm{P}$ solubilization abilities of 98 isolates were evaluated and we found that $39.8 \%$ of isolates exhibited the ability to show a clear zone around the colonies. The size of these clear zones fluctuated between 0.9 and $5.0 \mathrm{~mm}$, and the AF43 isolate obtained from the roots of Bala Doshi displayed the largest clear zone $(5.0 \mathrm{~mm})$ among all isolates (Table 2). Regarding P solubilization activity, Leaf star isolates showed the highest frequency of $\mathrm{P}$ solubilizers $(50 \%)$ among the 5 rice varieties (Fig. 2).

Among 98 isolates, $19.3 \%$ exhibited $\mathrm{K}$ solubilization activity. The size of the clear zones varied between 1.0 and $6.0 \mathrm{~mm}$ among the isolates. The AF13 isolate derived from the roots of Sorkhaq, showed the largest clear zone $(6.0 \mathrm{~mm})$ among all isolates (Table 2). Sorkhaq showed the highest frequency of effective $\mathrm{K}$ solubilizers $(30.4 \%)$, whereas the lowest frequency of K solubilizers was found (5.5\%) in Leaf Star among the rice varieties (Fig. 2).

Regarding siderophore production, 41 out of 98 isolates showed siderophore production via orange or yellow zone

Table 1. Soil sample description and number of isolates obtained from each site of soil sampling.

\begin{tabular}{llllll}
\hline $\begin{array}{l}\text { Soil } \\
\text { sampling } \\
\text { sites }\end{array}$ & $\begin{array}{l}\text { Number of } \\
\text { soil } \\
\text { samples }\end{array}$ & Latitude and longitude & Fields & $\mathrm{pH}^{\mathrm{a}}$ & $\begin{array}{l}\text { Total } \\
\text { number of } \\
\text { isolates }\end{array}$ \\
\hline Kabul & 1 & $34^{\circ} 31^{\prime} \mathrm{N}-69^{\circ} 11^{\prime} \mathrm{E}$ & Clover & $8.9 \pm 0.2$ & 10 \\
Baghlan & 6 & $36^{\circ} 08^{\prime} \mathrm{N}-68^{\circ} 42^{\prime} \mathrm{E}$ & Paddy & $8.0 \pm 0.1$ & 36 \\
Kunduz & 2 & $36^{\circ} 43^{\prime} \mathrm{N}-68^{\circ} 52^{\prime} \mathrm{E}$ & Paddy & $8.2 \pm 0.4$ & 8 \\
Takhar & 2 & $35^{\circ} 58^{\prime} \mathrm{N}-70^{\circ} 23^{\prime} \mathrm{E}$ & Paddy & $8.0 \pm 0.5$ & 17 \\
Badakhshan & 4 & $36^{\circ} 23^{\prime} \mathrm{N}-71^{\circ} 29^{\prime} \mathrm{E}$ & Paddy and Alfalfa & $8.2 \pm 0.1$ & 27 \\
\hline
\end{tabular}

${ }^{a}$ Measured with a pH meter in a 1:2.5 (w/v) soil and distilled water solution (42). 
Table 2. Sampling sites, details of isolate origins, closest relatives, and physiological characteristics.

\begin{tabular}{|c|c|c|c|c|c|c|c|c|c|c|c|}
\hline $\begin{array}{l}\text { Rice } \\
\text { varieties }\end{array}$ & $\begin{array}{l}\text { Isolate } \\
\text { name }\end{array}$ & $\begin{array}{l}\text { Soil } \\
\text { sampling site }\end{array}$ & Fields & $\begin{array}{l}\text { Origin of isolates } \\
\text { associated with rice }\end{array}$ & $\begin{array}{l}\text { Closest relative based on } 16 \mathrm{~S} \text { rRNA } \\
\text { gene sequencef }\end{array}$ & $\begin{array}{l}\text { IAA } \\
\text { production }\end{array}$ & $\mathrm{ARA}^{\mathrm{b}}$ & ${ }^{c}$ P-solubilization & ${ }^{\mathrm{d}} \mathrm{K}$-solubilization & ${ }^{\mathrm{e}} \mathrm{S}$-production & $\begin{array}{l}\text { Accession } \\
\text { numbers }\end{array}$ \\
\hline \multirow{7}{*}{ Leaf star } & AF5 & Baghlan & Paddy & Leaf & Pseudomonas brassicacearum $*(100 \%)$ & $8.4 \pm 0.2$ & $2.9 \pm 0.1$ & 0.0 & 0.0 & $6.0 \pm 0.8$ & LC015569 \\
\hline & AF19 & Baghlan & Paddy & Leaf & Rhizobium daejeonense $(99 \%)$ & $10.9 \pm 0.3$ & $2.7 \pm 0.2$ & 0.0 & 0.0 & $3.0 \pm 0.2$ & LC015583 \\
\hline & AF28 & Baghlan & Paddy & Leaf & Agrobacterium larrymoorei (99\%) & $4.2 \pm 0.1$ & 0.0 & $1.0 \pm 0.2$ & 0.0 & $1.0 \pm 0.1$ & LC015600 \\
\hline & AF113 & Baghlan & Paddy & Leaf & Acidovorax oryzae (100\%) & $2.8 \pm 0.4$ & 0.0 & $3.0 \pm 0.1$ & 0.0 & $6.0 \pm 0.8$ & LC015530 \\
\hline & AF52 & Takhar & Paddy & Root & Agrobacterium larrymoorei (99\%) & $9.4 \pm 1.6$ & 0.0 & $1.1 \pm 0.1$ & 0.0 & 0.0 & LC015601 \\
\hline & AF71 & Badakhshan & Alfalfa & Root & Paenibacillus pabuli (99\%) & $4.2 \pm 0.7$ & 0.0 & 0.0 & 0.0 & $5.0 \pm 0.7$ & LC015557 \\
\hline & AF90 & Kunduz & Paddy & Root & Variovorax paradoxus $(100 \%)$ & $3.2 \pm 0.5$ & 0.0 & 0.0 & $1.0 \pm 0.2$ & $1.0 \pm 0.0$ & LC015538 \\
\hline \multirow{12}{*}{ Sorkhaq } & AF9 & Kunduz & Paddy & Leaf & Pantoea ananatis (100\%) & $22.5 \pm 1.2$ & $3.4 \pm 0.3$ & $2.5 \pm 0.1$ & $4.0 \pm 0.5$ & $1.0 \pm 0.2$ & LC015551 \\
\hline & AF11 & Baghlan & Paddy & Leaf & Rhizobium rosettiformans (99\%) & $11.7 \pm 2.2$ & $0.5 \pm 0.0$ & 0.0 & 0.0 & 0.0 & LC015582 \\
\hline & AF16 & Kunduz & Paddy & Leaf & Xanthomonas sacchari $(99 \%)$ & $6.8 \pm 0.8$ & 0.0 & 0.0 & 0.0 & $1.0 \pm 0.1$ & LC015607 \\
\hline & AF22 & Badakhshan & Paddy & Leaf & Pseudomonas resinovorans (99\%) & $3.9 \pm 0.9$ & $0.2 \pm 0.0$ & 0.0 & 0.0 & 0.0 & LC015561 \\
\hline & AF23 & Takhar & Paddy & Leaf & Brevundimonas bullata $(99 \%)$ & $30.5 \pm 2.7$ & $2.3 \pm 0.2$ & 0.0 & 0.0 & 0.0 & LC015540 \\
\hline & AF84 & Baghlan & Paddy & Leaf & Rhizobium daejeonense (99\%) & $17.4 \pm 2.6$ & $629.1 \pm 23.8$ & 0.0 & 0.0 & 0.0 & LC015590 \\
\hline & AF137 & Kabul & Clover & Leaf & Pseudomonas putida $(100 \%)$ & $15.8 \pm 1.5$ & $647.4 \pm 27.4$ & $1.0 \pm 0.1$ & $1.0 \pm 0.1$ & 0.0 & LC015575 \\
\hline & $\mathrm{AF} 42$ & Badakhshan & Paddy & Root & Enterobacter ludwigii (99\%) & $17.1 \pm 0.4$ & $3.9 \pm 0.1$ & $2.0 \pm 0.2$ & $2.0 \pm 0.1$ & $1.0 \pm 0.1$ & LC015545 \\
\hline & AF74 & Badakhshan & Paddy & Root & Enterobacter ludwigii $(99 \%)$ & $18.8 \pm 1.0$ & $0.3 \pm 0.0$ & $2.0 \pm 0.2$ & $4.2 \pm 0.7$ & $3.0 \pm 0.5$ & LC015546 \\
\hline & AF91 & Baghlan & Paddy & Root & Paenibacillus bracinonensis (99\%) & 0.0 & $0.3 \pm 0.0$ & $1.5 \pm 0.3$ & 0.0 & 0.0 & LC015555 \\
\hline & AF117 & Baghlan & Paddy & Root & Paenibacillus barcinonensis (99\%) & 0.0 & $0.5 \pm 0.0$ & 0.0 & 0.0 & 0.0 & LC015556 \\
\hline & AF135 & Kabul & Clover & Root & Enterobacter ludwigii $(100 \%)$ & $74.9 \pm 4.7$ & $0.5 \pm 0.0$ & $1.5 \pm 0.4$ & 0.0 & $2.0 \pm 0.3$ & LC015542 \\
\hline \multirow{18}{*}{$\begin{array}{l}\text { Bala } \\
\text { Doshi }\end{array}$} & AF100 & Takhar & Paddy & Leaf & Pseudomonas chengduensis (99\%) & 0. & 0.0 & 0. & 0.0 & $6.0 \pm 0.7$ & LC015559 \\
\hline & AF51 & Takhar & Paddy & Leaf & Rhizobium daejeonense (99\%) & $10.6 \pm 1.0$ & $363.3 \pm 11.4$ & $1.0 \pm 0.1$ & 0.0 & 0.0 & LC015586 \\
\hline & AF69 & Takhar & Paddy & Leaf & Ensifer adhaerens (99\%) & $2.0 \pm 1.0$ & 0.0 & 0.0 & 0.0 & 0.0 & LC015581 \\
\hline & AF73 & Takhar & Paddy & Leaf & Pseudomonas putida $(100 \%)$ & $7.4 \pm 0.8$ & $14.1 \pm 1.1$ & $1.5 \pm 0.4$ & 0.0 & $6.5 \pm 0.4$ & LC015579 \\
\hline & AF86 & Baghlan & Paddy & Leaf & Pseudomonas brassicacearum * $(100 \%)$ & $10.0 \pm 2.4$ & $0.8 \pm 0.0$ & 0.0 & 0.0 & $6.0 \pm 0.9$ & LC015572 \\
\hline & AF6 & Baghlan & Paddy & Leaf & Agrobacterium tumefaciens (99\%) & $16.5 \pm 0.9$ & 0.0 & $1.0 \pm 0.3$ & 0.0 & 0.0 & LC015597 \\
\hline & AF79 & Kunduz & Paddy & Leaf & Enterobacter ludwigii (99\%) & $47.4 \pm 3.0$ & $0.4 \pm 0.1$ & $1.0 \pm 0.1$ & 0.0 & $1.0 \pm 0.1$ & LC015547 \\
\hline & $\mathrm{AF} 30$ & Takhar & Paddy & Root & Rhizobium daejeonense (99\%) & $12.3 \pm 0.4$ & $96.3 \pm 6.5$ & 0.0 & 0.0 & 0.0 & LC015585 \\
\hline & AF32 & Kunduz & Paddy & Root & Enterobacter ludwigii ( $99 \%)$ & $23.6 \pm 2.6$ & 0.0 & $1.3 \pm 0.4$ & $4.0 \pm 0.9$ & 0.0 & LC015544 \\
\hline & AF43 & Takhar & Paddy & Root & Pseudomonas mosselii (100\%) & $7.6 \pm 0.8$ & 0.0 & $5.0 \pm 0.6$ & 0.0 & $3.0 \pm 0.5$ & LC015563 \\
\hline & AF46 & Baghlan & Paddy & Root & Pseudomonas brassicacearum* (99\%) & $3.1 \pm 1.8$ & $16.0 \pm 0.9$ & 0.0 & 0.0 & $6.0 \pm 0.3$ & LC015571 \\
\hline & AF76 & Takhar & Paddy & Root & Pseudomonas putida $(100 \%)$ & $9.9 \pm 1.4$ & $1.0 \pm 0.1$ & 0.0 & 0.0 & $7.0 \pm 0.9$ & LC015578 \\
\hline & AF7 & Baghlan & Paddy & Root & Ralstonia insidiosa $(100 \%)$ & $2.7 \pm 0.4$ & $2.8 \pm 0.2$ & 0.0 & 0.0 & 0.0 & LC015529 \\
\hline & AF8 & Takhar & Paddy & Root & Rhizobium borbori $(99 \%)$ & $6.5 \pm 0.8$ & $1.5 \pm 0.4$ & 0.0 & 0.0 & $1.0 \pm 0.1$ & LC015592 \\
\hline & AF130 & Baghlan & Paddy & Root & Brevundimonas diminuta (99\%) & $3.2 \pm 1.8$ & $1.2 \pm 0.0$ & 0.0 & 0.0 & 0.0 & LC015539 \\
\hline & AF77 & Baghlan & Paddy & Root & N.D. & $2.1 \pm 0.6$ & $0.2 \pm 0.0$ & $0.9 \pm 0.2$ & 0.0 & 0.0 & N.D. \\
\hline & AF96 & Takhar & Paddy & Root & Pseudomonas putida (100\%) & $7.8 \pm 1.4$ & 0.0 & $1.2 \pm 0.5$ & $2.0 \pm 0.3$ & $6.0 \pm 0.4$ & LC015580 \\
\hline & AF99 & Kunduz & Paddy & Root & Pseudomonas oryzihabitans (99\%) & $6.5 \pm 0.6$ & $1.0 \pm 0.0$ & 0.0 & 0.0 & $4.0 \pm 0.9$ & LC015574 \\
\hline \multirow{5}{*}{$\begin{array}{l}\text { Look } \\
\text { Andarab }\end{array}$} & AF54 & Badakhshan & Paddy & Leaf & Xanthomonas sacchari (99\%) & $5.5 \pm 0.4$ & 0.0 & 0.0 & 0.0 & 0.0 & LC015609 \\
\hline & AF112 & Badakhshan & Alfalfa & Leaf & Pseudomonas plecoglossicida (99\%) & $11.5 \pm 1.3$ & $0.3 \pm 0.0$ & $2.0 \pm 0.2$ & 0.0 & 0.0 & LC015560 \\
\hline & AF40 & Takhar & Paddy & Root & Rhizobium borbori (99\%) & $10.8 \pm 0.9$ & $1.7 \pm 0.2$ & 0.0 & 0.0 & 0.0 & LC015591 \\
\hline & AF75 & Badakhshan & Paddy & Root & Rhizobium daejeonense (99\%) & $13.5 \pm 0.7$ & $345.2 \pm 14.4$ & 0.0 & 0.0 & 0.0 & LC015589 \\
\hline & AF124 & Badakhshan & Paddy & Root & Rhizobium daejeonense (99\%) & $19.2 \pm 3.4$ & $218.3 \pm 23.5$ & 0.0 & 0.0 & 0.0 & LC015587 \\
\hline \multirow{6}{*}{$\begin{array}{l}\text { Monda } \\
\text { Laghman }\end{array}$} & AF134 & Kabul & Clover & Leaf & cter ludwigii (99\%) & $92.4 \pm 5.9$ & $1.1 \pm 0.1$ & 0.0 & 0.0 & $2.5 \pm 0.2$ & LC015549 \\
\hline & AF26 & Takhar & Paddy & Root & Agrobacterium tumefaciens (100\%) & $8.6 \pm 0.5$ & 0.0 & 0.0 & $1.0 \pm 0.2$ & 0.0 & LC015595 \\
\hline & AF105 & Badakhshan & Paddy & Root & Enterobacter ludwigii (99\%) & $32.3 \pm 2.0$ & $1.2 \pm 0.1$ & 0.0 & 0.0 & 0.0 & LC015541 \\
\hline & AF129 & Badakhshan & Paddy & Root & Pseudomonas brassicacearum* (99\%) & $2.9 \pm 0.8$ & $3.9 \pm 0.4$ & 0.0 & 0.0 & $3.0 \pm 0.2$ & LC015570 \\
\hline & AF29 & Badakhshan & Paddy & Root & Xanthomonas sacchari (99\%) & $8.4 \pm 2.5$ & 0.0 & 0.0 & $4.0 \pm 0.8$ & $4.0 \pm 0.3$ & LC015608 \\
\hline & AF26 & Takhar & Paddy & Root & Agrobacterium tumefaciens $(100 \%)$ & $8.6 \pm 0.5$ & 0.0 & 0.0 & $1.0 \pm 0.2$ & 0.0 & LC015595 \\
\hline
\end{tabular}

${ }^{\text {a }}$ Amount of IAA produced ( $\mu \mathrm{g}$ IAA per mL per $10^{6}$ cells).

${ }^{b}$ Acetylene reduction assay (ARA). Values represent activity expressed as $\mathrm{nmol} \mathrm{C}_{2} \mathrm{H}_{4} \mathrm{~h}^{-1} 10^{-6}$ cells.

${ }^{\mathrm{c}} \mathrm{P}$-solubilizing activity. Units represent size of clear zone (in $\mathrm{mm}$ ) caused by dissolution of calcium phosphate.

${ }^{\mathrm{d}} \mathrm{K}$-solubilizing activity. Units represent size of clear zone (in $\mathrm{mm}$ ) caused by dissolution of potassium mineral.

${ }^{\mathrm{e}}$ Siderophore production by bacterial strains. Units represent size of orange or yellow zone (in $\mathrm{mm}$ ).

* Pseudomonas brassicacearum subsp. Brassicacearum.

I Values into parentheses indicate the percent of similarity between 16S RNA gene sequences of the isolates and those of known microorganisms of the NCBI GenBank.

N.D. means not determined.

formation around the colonies. A high frequency of siderophore producers $(50 \%)$ was observed in the Leaf Star rice variety (Fig. 2). AF95 and AF76 isolates from Leaf star and Bala Doshi showed a high potential for siderophore production $(7.0 \mathrm{~mm})$ (Table 2). AF5, 95, and 113 of Leaf star and AF46, 86, 96, and 100 of Bala Doshi showed higher siderophore production levels at more than $6.0 \mathrm{~mm}$ (Table 2).

\section{Genetic characterization}

Among 98 isolates, 81 were selected and a DNA fragment of approximately 1,363-1,456 bp from their 16S rRNA genes was sequenced and analyzed. Based on 16S rRNA sequences, 81 isolates were categorized into 16 different genera; Acidovorax, Agrobacterium, Achromobacter, Bacillus, Brevundimonas, Ensifer, Enterobacter, Microbacterium, 


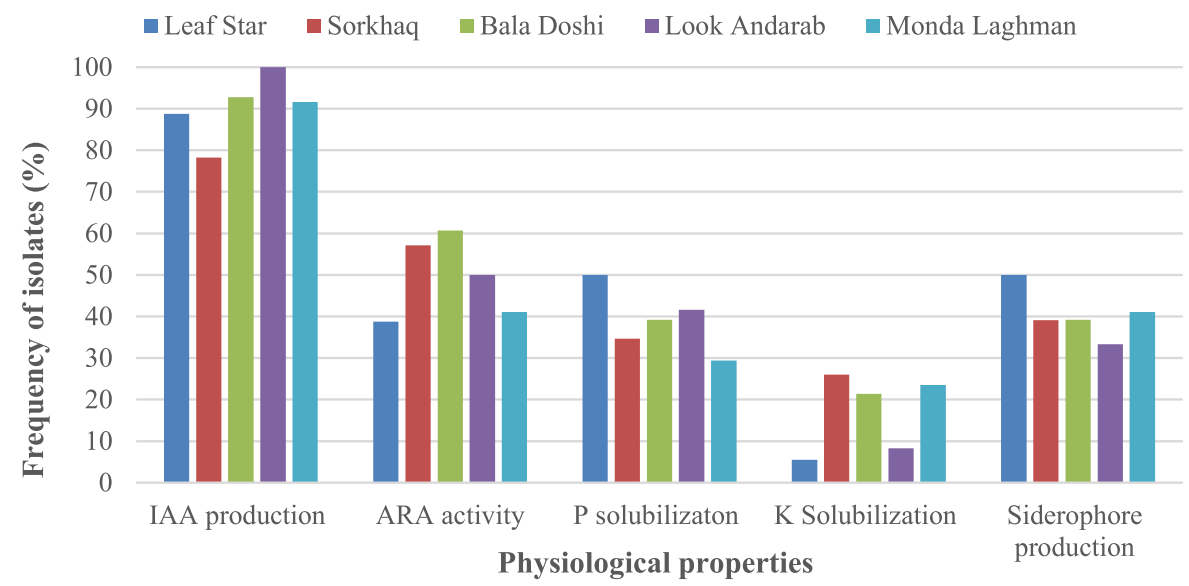

Fig. 2. Frequencies of isolates from various rice varieties showing different physiological characteristics.

Paenibacillus, Pantoea, Pseudomonas, Pseudoxanthomonas, Ralstonia, Rhizobium, Variovorax, and Xanthomonas (Fig. 3 ). The dominant genus was Pseudomonas (24.6\%), followed by Rhizobium (13.5\%). The 16S rRNA phylogenetic tree was divided into six groups (Fig. 3, G1-G6).

The G1 group included $P$. putida, $P$. brassicacearum, $P$. oryzihabitans, $P$. chengduensis, $P$. monteilii, $P$. mosselii, $P$. plecoglossicida, $P$. resinovorans, and $P$. straminea. Of the 6 isolates belonging to $P$. putida, the AF137 strain isolated from the leaves of the Sorkhaq rice cultivar showed the highest ARA activity among all isolates (Table 2). We detected 6 isolates of $P$. brassicacearum, including AF5, AF86, and AF46 (as shown in Table 2), in the roots and leaves of rice plants. To the best of our knowledge, this is the first study to show the relationship between an epiphyte and endophyte on rice plants. We also found AF100 (P. chengduensis), AF112 (P. plecoglossicida), AF22 (P. resinovorans), and AF95 ( $P$. straminea) in the leaf part and AF43 ( $P$. mosselii) in the root part of rice plants.

The G2 group consisted of two genera: Pantoea (2 isolates) and Enterobacter (9 isolates). These 11 isolates displayed high IAA production levels among all isolates. The G3 group comprised 10 isolates showing close similarities to Xanthomonas (8 isolates) and Pseudoxanthomonas (2 isolates) species. The G4 group contained 11 isolates related to different genera; Achromobacter (1 isolate), Ralstonia (1 isolate), Variovorax (1 isolate), and Acidovorax (8 isolates).

The G5 group of isolates included 4 genera (Brevundimonas, Ensifer, Agrobacterium, and Rhizobium). Among the 11 isolates related to the Rhizobium genus, 8 were categorized as $R$. daejeonense; two isolates (AF8 and AF40) as R. borbori, and one as $R$. rosettiformans (AF11). In the ARA evaluation, $R$. daejeonense isolates were found to be promising diazotrophs showing high ethylene production levels among all isolates (Table 2). Furthermore, the AF8 (R. borbori) and AF11 ( $R$. rosettiformans) isolates exhibited nitrogenase activity under free living conditions (Table 2). The isolation of $R$. borbori from the leaves and $R$. rosettiformans from the roots of rice plants and their nitrogen fixation potentials is another novel result. We detected two Brevundimonas strains; one strain AF23 (Brevundimonas bullata) obtained from the leaves of Sorkhaq and another strain AF130 (B. diminuta) isolated from the roots of Bala Doshi. Both strains (AF23 and AF130) exhibited nitrogenase activity. To the best of our knowledge, the relationship between $B$. bullata and rice and the nitrogen fixation potentials of both strains ( $B$. diminuta and $B$. diminuta) has been demonstrated here for the first time.

The G6 group of isolates showed high similarities to Actinobacteria (3 isolates) and Firmicutes (Bacillus and Paenibacillus). We found three Paenibacillus strains; P. pabuli (AF71) isolated from Leaf Star in Badakhshan soils, and $P$. bracinonensis (AF91 and AF117) obtained from the roots of Sorkhaq in Baghlan soils. Both strains of P. bracinonensis (AF91 and AF117) exhibited nitrogenase activity.

\section{Effects of bacterial inoculation on rice growth}

The inoculation effects of 24 isolates were evaluated on rice plants grown for $21 \mathrm{~d}$. All bacterial isolates generally exerted positive effects on different plant growth parameters, as shown in Table 3. The isolate AF74 (E. ludwigii), which was isolated from the roots of Sorkhaq, significantly increased $(P<0.05)$ shoot heights $(55.7 \mathrm{~cm})$ over those of the un-inoculated control. All of the isolates also exerted positive effects on root lengths. Root lengths varied between 7.3 and $15.6 \mathrm{~cm}$, and significant variations were observed in response to the AF6 (A. tumefaciens), AF113 (A. oryzae), AF76 ( $P$. Putida), AF46 (P. brassicacearum), and AF30 (R. daejeonense) isolates (Table 3$)$. In shoot dry weight, 17 isolates $(70.8 \%$ of the total) resulted in significant increases $(P<0.05)$ in root dry weights over those of the un-inoculated plants. This enhancement varied between 60.55 and $260.3 \mathrm{mg}$ plant $^{-1}$, and the most significant increases were recorded for inoculated plants (221.1 to $260.3 \mathrm{mg} \mathrm{plant}^{-1}$ ) with AF74 (E. ludwigii), AF79 (E. ludwigii), AF46 (P. brassicacearum), AF42 (E. ludwigii), $\mathrm{AF} 28$ (A. larrymoorei), and AF112 (P. plecoglossicida) isolates (Table 3). Similarly, root dry weights exhibited significant increases in response to inoculations with 18 isolates (75.0\%). The most significant increases were observed between 122.6 and $140.2 \mathrm{mg} \mathrm{plant}^{-1}$ following inoculations with the AF9 ( $P$. ananatis), $\mathrm{AF} 30$ ( $R$. daejeonense), $\mathrm{AF} 52$ (A. larrymoorei), AF74, and AF79 (E. ludwigii) isolates (Table 3). The isolates obtained from Bala Doshi rice cultivars promoted rice growth slightly more efficiently than the other rice cultivar isolates (Table 3). 


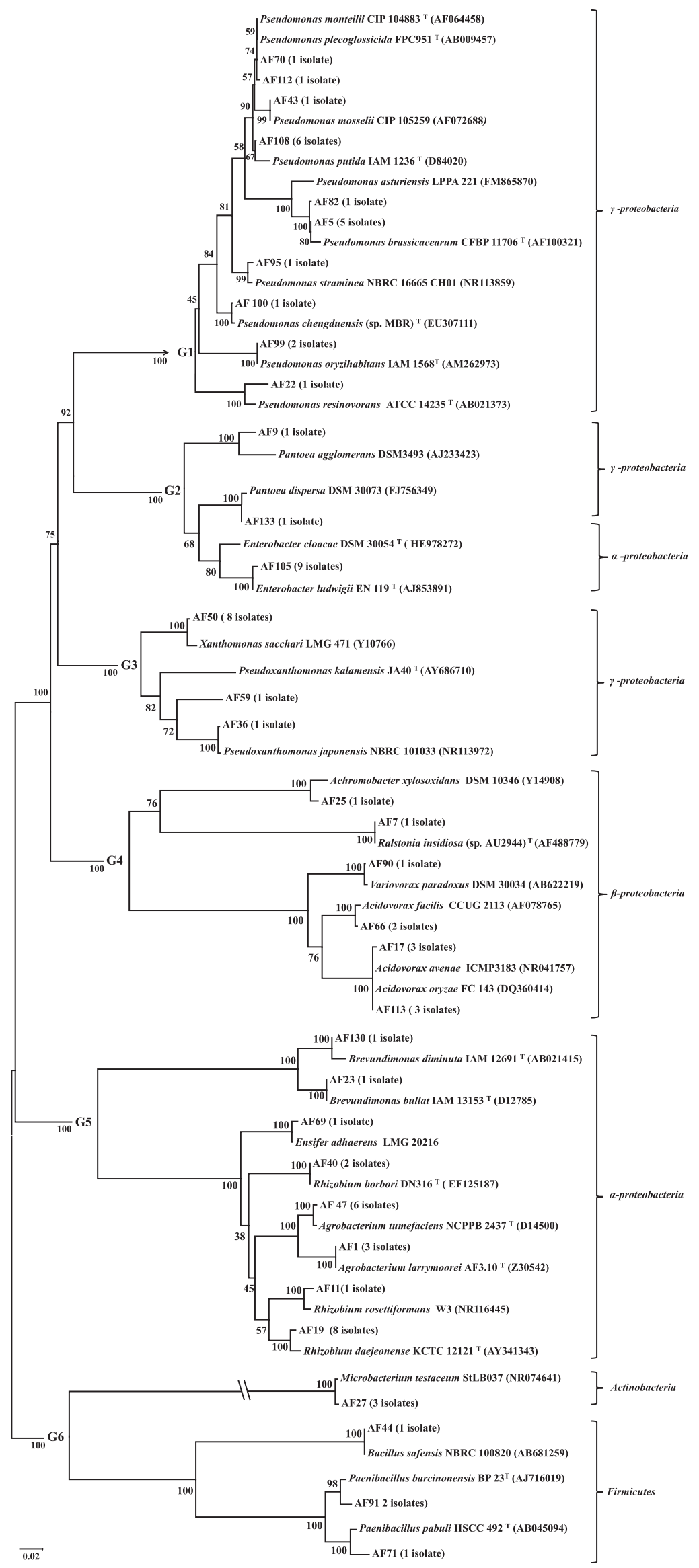

Fig. 3. Phylogenetic trees of $16 \mathrm{~S}$ rRNA constructed using partial nucleotide sequences $(1,363 \mathrm{bp})$ from 81 isolates and type strains of species belonging to different genera. The numbers at the nodes indicate the level of bootstrap support, based on a neighbor-joining analysis. 
Table 3. Summary effects of inoculating isolates on rice plants

\begin{tabular}{|c|c|c|c|c|c|c|c|}
\hline $\begin{array}{l}\text { Host rice } \\
\text { varieties }\end{array}$ & $\begin{array}{l}\text { Isolate } \\
\text { names }\end{array}$ & Bacterial species & $\begin{array}{l}\text { Origin of isolate } \\
\text { associated with } \\
\text { rice plant }\end{array}$ & $\begin{array}{l}\text { Shoot height } \\
(\mathrm{cm})\end{array}$ & $\begin{array}{l}\text { Root length } \\
(\mathrm{cm})\end{array}$ & $\begin{array}{l}\text { Shoot dry } \\
\text { weight } \\
\text { (mg/plant) }\end{array}$ & $\begin{array}{l}\text { Root dry weight } \\
\text { (mg/plant) }\end{array}$ \\
\hline & Control & . & . & $43.6 \pm 2.1^{\mathrm{a}}$ & $8.3 \pm 1.4$ & $83.9 \pm 3.6$ & $44.5 \pm 3.7$ \\
\hline \multirow{4}{*}{ Leaf Star } & AF19 & Rhizobium daejeonense $(99 \%)$ & Leaf & $47.6 \pm 5.0$ & $11.0 \pm 1.0$ & $217.0 \pm 10.2^{*}$ & $95.5 \pm 9.3 *$ \\
\hline & AF28 & Agrobacterium larrymoorei (99\%) & Leaf & $46.3 \pm 1.2$ & $13.6 \pm 0.6$ & $221.1 \pm 49.2 *$ & $98.2 \pm 12.1^{*}$ \\
\hline & AF113 & Acidovorax oryzae $(100 \%)$ & Leaf & $50.3 \pm 2.5$ & $15.7 \pm 2.1^{*}$ & $106.6 \pm 15.5$ & $66.9 \pm 8.9$ \\
\hline & AF52 & Agrobacterium larrymoorei (99\%) & Root & $49.0 \pm 3.6$ & $12.5 \pm 2.5$ & $127.5 \pm 18.6$ & $122.6 \pm 16.4^{*}$ \\
\hline \multirow{5}{*}{ Sorkhaq } & AF9 & Pantoea ananatis $(100 \%)$ & Leaf & $46.7 \pm 5.8$ & $11.7 \pm 2.3$ & $152.4 \pm 19.8$ & $131.0 \pm 8.5^{*}$ \\
\hline & AF22 & Pseudomonas resinovorans $(99 \%)$ & Leaf & $49.2 \pm 1.7$ & $12.3 \pm 1.5$ & $217.3 \pm 18.9^{*}$ & $114.8 \pm 18.5^{*}$ \\
\hline & AF16 & Xanthomonas sacchari $(99 \%)$ & Leaf & $46.0 \pm 3.6$ & $9.3 \pm 4.2$ & $147.7 \pm 22.8$ & $69.2 \pm 10.8$ \\
\hline & AF42 & Enterobacter ludwigii (99\%) & Root & $46.6 \pm 1.5$ & $11.2 \pm 1.0$ & $227.9 \pm 35.1 *$ & $107.7 \pm 11.3 *$ \\
\hline & AF74 & Enterobacter ludwigii $(99 \%)$ & Root & $55.7 \pm 5.1^{*}$ & $12.7 \pm 0.6$ & $260.3 \pm 12.3^{*}$ & $130.2 \pm 21.5^{*}$ \\
\hline \multirow{9}{*}{$\begin{array}{l}\text { Bala } \\
\text { Doshi }\end{array}$} & AF20 & Rhizobium daejeonense (99\%) & Leaf & $50.0 \pm 3.0$ & $12.3 \pm 2.5$ & $220.0 \pm 17.3^{*}$ & $95.9 \pm 9.7 *$ \\
\hline & AF6 & Agrobacterium tumefaciens (99\%) & Leaf & $48.7 \pm 3.2$ & $15.0 \pm 1.0^{*}$ & $166.6 \pm 10.6^{*}$ & $95.3 \pm 20.2 *$ \\
\hline & AF79 & Enterobacter ludwigii (99\%) & Leaf & $48.3 \pm 2.1$ & $10.6 \pm 1.2$ & $249.8 \pm 19.8^{*}$ & $131.0 \pm 8.5^{*}$ \\
\hline & AF76 & Pseudomonas putida (100\%) & Root & $51.6 \pm 1.5$ & $13.3 \pm 2.5^{*}$ & $167.3 \pm 12.1^{*}$ & $73.7 \pm 7.4$ \\
\hline & AF96 & Pseudomonas putida $(100 \%)$ & Root & $46.7 \pm 1.5$ & $13.3 \pm 0.6$ & $211.6 \pm 12.0^{*}$ & $99.1 \pm 2.4 *$ \\
\hline & AF43 & Pseudomonas mosselii (100\%) & Root & $49.0 \pm 2.6$ & $12.3 \pm 0.6$ & $161.3 \pm 16.9 *$ & $67.7 \pm 1.9$ \\
\hline & AF46 & Pseudomonas brassicacearum (99\%) & Root & $48.3 \pm 2.9$ & $15.6 \pm 1.5^{*}$ & $239.4 \pm 9.2 *$ & $95.7 \pm 12.6^{*}$ \\
\hline & AF30 & Rhizobium daejeonense $(99 \%)$ & Root & $48.6 \pm 3.2$ & $14.7 \pm 2.3^{*}$ & $218.6 \pm 28.0^{*}$ & $140.2 \pm 13.9 *$ \\
\hline & AF99 & Pseudomonas oryzihabitans $(99 \%)$ & Root & $48.6 \pm 3.1$ & $12.3 \pm 0.6$ & $195.1 \pm 24.6^{*}$ & $102.3 \pm 18.7^{*}$ \\
\hline \multirow{4}{*}{$\begin{array}{l}\text { Look } \\
\text { Andarab }\end{array}$} & AF54 & Xanthomonas sacchari $(99 \%)$ & Leaf & $48.0 \pm 1.0$ & $13.3 \pm 2.9$ & $203.9 \pm 16.9 *$ & $94.1 \pm 8.8^{*}$ \\
\hline & AF114 & Agrobacterium tumefaciens (100\%) & Leaf & $42.0 \pm 4.0$ & $14.6 \pm 1.2$ & $118.9 \pm 11.6$ & $74.7 \pm 11.0$ \\
\hline & AF112 & Pseudomonas plecoglossicida (99\%) & Leaf & $50.6 \pm 3.8$ & $14.3 \pm 2.3$ & $226.0 \pm 22.8^{*}$ & $104.3 \pm 18.9 *$ \\
\hline & AF124 & Rhizobium daejeonense (99\%) & Root & $50.7 \pm 0.6$ & $13.5 \pm 1.3$ & $205.1 \pm 24.0^{*}$ & $103.2 \pm 9.4^{*}$ \\
\hline \multirow{2}{*}{$\begin{array}{l}\text { Monda } \\
\text { Laghman }\end{array}$} & AF105 & Enterobacter ludwigii (99\%) & Root & $43.7 \pm 5.8$ & $8.7 \pm 2.1$ & $93.7 \pm 12.3$ & $49.0 \pm 1.8$ \\
\hline & AF29 & Xanthomonas sacchari $(99 \%)$ & Root & $47.3 \pm 9.9$ & $11.0 \pm 2.6$ & $155.1 \pm 25.5$ & $90.0 \pm 4.8^{*}$ \\
\hline \multirow{2}{*}{$\begin{array}{l}\text { Positive } \\
\text { controls }\end{array}$} & TUAT 1 & Bacillus pumilus & . & $51.3 \pm 4.5$ & $11.7 \pm 1.4$ & $253.2 \pm 16.7^{*}$ & $107.3 \pm 10.6^{*}$ \\
\hline & TS- 13 & Azospirillum brasilense & . & $50.3 \pm 3.5$ & $11.3 \pm 0.6$ & $223.3 \pm 20.8^{*}$ & $103.3 \pm 5.8^{*}$ \\
\hline
\end{tabular}

a Mean value ( $n=3$ replicates)

* Value is significantly different from the control, within each column $(P<0.05)$

T Values into parentheses indicate the percent of similarity between 16S RNA gene sequences of the isolates and those of known microorganisms of the NCBI GenBank.

\section{Discussion}

In a previous study (19), we investigated the colonization of rice plants by different PGPR and compared their physiological characteristics and growth potentials related to each plant rhizosphere. In the present study, we examined the influence of various rice cultivars on PGPR colonization, and compared the physiological properties of these PGPR, which were obtained from different rice cultivars using different soil samples (mainly paddy fields).

IAA production is one of the important PGP traits of PGPR. The production of IAA by microbial isolates varies greatly among different species and strains of the same species and is also influenced by culture conditions, growth stages, and the availability of substrates (32). We assessed IAA production by 98 isolates obtained from different rice cultivars, and found that $100 \%$ of strains isolated from Look Andarab exhibited the ability to produce IAA among the 5 rice cultivars. Approximately $90 \%$ of the isolates from all rice cultivars (Leaf Star, Sorkhaq, Bala Doshi, Look Andarab, and Monda Laghman) showed the ability to produce IAA (Fig. 2). The reason why $100 \%$ of the isolates obtained from Look Andarab showed IAA production remains unclear; however, since Look Andarab is a cold-tolerant variety cultivated in temperate regions, this ability may be related to plant characteristics that allow for colonization by many IAA producers isolates. The largest amount of IAA produced was found in one endophytic PGPR, AF134 (E. ludwigii), which was isolated from the leaves of Monda Laghman (Table 2). Furthermore, the other isolates of Enterobacter species produced large amounts of IAA. Similarly, the potential of Enterobacter species to produce large amounts of IAA has been described in previous studies $(19,32,39)$.

Nitrogen fixation by PGPR is another mechanism involved in plant growth promotion, and certain PGPR exhibit this potential. Associative diazotrophs are considered to play important roles in increasing plant productivity and decreasing the use of chemical fertilizers. In our assay, $60 \%$ of bacterial isolates from Bala Doshi exhibited nitrogenase activity; and this was the highest frequency of nitrogen-fixing bacteria among the five rice cultivars (Fig. 2). $R$. daejeonense isolates showed high nitrogen fixation activities among the studied isolates. Similarly, in a previous study, we isolated one effective nitrogen-fixing $R$. daejeonense from Japanese soil (19). $R$. daejeonense also appears to be a promising nitrogen-fixing bacteria in Afghan soils. AF137, an endophytic bacterium of rice leaves, showed the highest nitrogenase activity amongst all of the rice cultivar isolates examined (Table 2). Furthermore, AF7 isolated from the roots of Bala Doshi in Baghlan soils showed nitrogen fixation potential and IAA production. To the best of our knowledge, the isolation of Ralstonia insidiosa from rice plants and its ability to fix nitrogen has been demonstrated here for the first time. 
$\mathrm{P}$ is the second important nutrient for plants and affects several characteristics of plant growth. P-solubilizing bacteria play an important role in releasing $\mathrm{P}$ from inorganic and organic pools in soil and provide $\mathrm{P}$ to plants via solubilization and mineralization. We assessed the $\mathrm{P}$ solubilization abilities of 98 isolates, and approximately $39 \%$ exhibited the ability to solubilize P mineral (tricalcium phosphate). AF43 (P. mosselii) obtained from the roots of Bala Doshi exhibited the highest P-solubilizing ability (Table 2). Similar findings on the P-solubilizing ability of $P$. mosselii have been reported $(22,35)$.

$\mathrm{K}$ is an essential plant nutrient that plants need for growth and reproduction. The majority of $\mathrm{K}$ in soil exists in various insoluble forms (rocks, minerals, and sedimentary materials), and $\mathrm{K}$-solubilizing bacteria release solid $\mathrm{K}$ into available $\mathrm{K}$, which is then directly absorbed by plants (45). However, under paddy field conditions, $\mathrm{K}$ solubilization may not be a major issue because PGPR may partially assist in the K-solubilizing process. In the present study, $19.4 \%$ of isolates exhibited K-solubilizing activity and the highest frequency of $\mathrm{K}$ solubilizers was observed in Sorkhaq isolates (30.4\%). The AF13 isolate (Enterobacter ludwigii), which was obtained from the roots of Sorkhaq isolate rice cultivars, exhibited the maximum K-solubilizing activity among all isolates (Table 2). Furthermore, Zhang and Kong (45) recently reported the K-solubilizing activity of Enterobacter species (4 strains). The AF90 isolate (Variovorax paradoxus) obtained from the roots of Leaf star solubilized $\mathrm{K}$ mineral and produced siderophores (Table 2). To the best of our knowledge, the isolation of $V$. paradoxus from rice plants and the above mentioned physiological properties by that isolate have been described here for the first time.

Siderophores are low-molecular-weight iron chelators that directly promote plant growth by binding to ferric oxides and making them available for plants or indirectly by binding to the available forms of iron in soil and making them unavailable to pathogens (30). In our assay, $41.8 \%$ of isolates produced siderophores, and Leaf Star isolates showed the highest frequency of siderophore producers among the 5 rice cultivars (Fig. 2). Pseudomonas species were more active for siderophore production than the species of other genera (Table 2). The ability of Pseudomonas species to function as siderophore producers has been reported previously (1).

We sequenced the $16 \mathrm{~S}$ rRNA genes of 81 isolates to assess PGPR diversity in Afghan soils (Supplementary material). The occurrence and distribution of microbial communities in the soil and rhizosphere are influenced by many factors, including root morphology, the stage of plant growth, root exudates, the physical and chemical properties of soil (5), plant species (18), soil type (9), soil depth (26), and cultivation practices (tillage/crop rotation) (29). An arid and semi-arid climate and Afghanistan topography resulted in different physical and chemical soil properties. Under these condition, the present results showed a higher distribution of Pseudomonas species in Afghan soils, particularly in paddy fields, than other bacterial genera. Regardless of the 17 non-characterized PGPR isolates in the present study, we found some clear differences among the colonization of rice cultivars by different genera of PGPR. For example, we did not detect Xanthomonas species in Bala Doshi or Leaf Star, Agrobacterium species in Sorkhaq, Rhizobium species in Monda Laghman, or Acidovorax species in Look Andarab. Among the 22 Pseudomonas species, 10 strains were found in Bala Doshi and four in Look Andarab (Supplementary material). The origin and common cultivation area of Bala Doshi and Look Andarab rice cultivars are related to the same province (Baghlan). Moreover, there were some PGPR unique to specific rice cultivars, such as $B$. safensis in Monda Laghman, V. paradoxus in Leaf Star, and Ensifer adhaerens in Bala Doshi isolates (Table 2). Many biotic and abiotic factors influence the colonization of plants by different or specific PGPR. Host specificity may be one factor influencing the colonization of PGPR to diverse crops. Regarding host specificity, Elbeltagy et al. (13) demonstrated that an endophytic bacterium (Herbaspirillum sp. strain $\mathrm{B} 501$ ) isolated from the stems of wild rice did not colonize cultivated rice after inoculation under aseptic conditions. Similarly, Bhattarai and Hess (7) reported that strains isolated from the same host plant were more efficient at improving plant growth.

Based on physiological characteristics and sampling sites, we selected 24 isolates for the plant growth test and evaluated their growth potential on rice plants. These isolates positively affected different growth parameters of rice plants. In the plant growth test, significantly greater increases in shoot and root dry weights were observed in Pseudomonas and Rhizobium species than in the species of other genera (Table 3 ). The potential of Pseudomonas and Rhizobium species as rice plant growth promoters has been reported in previous studies $(8,28,33,43)$. Furthermore, we found that PGPR isolated from Bala Doshi rice cultivars were significantly more effective at promoting plant growth than other rice cultivar isolates (Table 3). This may be due to the host specificity of Bala Doshi rice cultivars to the isolates obtained. As described above, Bhattarai and Hess reported similar findings (7).

In the present study, 98 bacterial strains were isolated from the leaves and roots of 5 rice cultivars using 15 soil samples as inoculants. We then examined the morphological, physiological, and genetic characteristics of these isolates to evaluate their potential as biofertilizers for rice crops. The results obtained revealed that AF74 (E. ludwigii), AF79 (E. ludwigii), AF46 (P. brassicacearum), AF112 (P. plecoglossicida), and AF30 (Rhizobium daejeonense) are potential candidates as biofertilizers for rice crops in Afghanistan. The use of biofertilizers may decrease the negative effects of chemical fertilizers on the environment and develop a sustainable agriculture in Afghanistan. However, further studies are required prior to the application of these PGPR in field conditions.

\section{Acknowledgements}

This study was supported by the Special Research Fund of the Ministry of Education, Culture, Sports, Science and Technology (MEXT), Japan titled "Research and development of security and safe crop production to reconstruct agricultural lands in Fukushima prefecture based on novel techniques to remove radioactive compounds using advanced biofertilizer and plant protection strategies".

\section{References}

1. Ahmad, F., I. Ahmad, and M.S. Khan. 2008. Screening of free-living rhizospheric bacteria for their multiple plant growth promoting activities. Microbiol. Res. 163:173-181. 
2. Alexander, D.B., and D.A. Zuberer. 1991. Use of chrome azurol S reagents to evaluate siderophore production by rhizosphere bacteria. Biol. Fertil. Soils 12:39-45.

3. Araújo, A.E.S., V.L.D. Baldani, P.S. Galisa, J.A. Pereira, and J.I. Baldani. 2013. Response of traditional upland rice varieties to inoculation with selected diazotrophic bacteria isolated from rice cropped at the Northeast region of Brazil. Appl. Soil Ecol. 64:49-55.

4. Beneduzi, A., D. Peres, P.B. Costa, M.H. Zanettini, and L.M. Passaglia. 2008. Genetic and phenotypic diversity of plant-growth-promoting bacilli isolated from wheat fields in southern Brazil. Res. Microbiol. 159:244-250.

5. Beneduzi, A., D. Peres, L.K. Vargas, M.H. Bodanese-Zanettini, and L.M. Passaglia. 2008. Evaluation of genetic diversity and plant growth promoting activities of nitrogen-fixing bacilli isolated from rice fields in South Brazil. Appl. Soil Ecol. 39:311-320.

6. Bernier, J., G.N. Atlin, R. Serraj, A. Kumar, and D. Spaner. 2008. Breeding upland rice for drought resistance. J. Sci. Food Agric. 88:927-939.

7. Bhattarai, T., and D. Hess. 1993. Yield responses of Nepalese spring wheat (Triticum aestivum L.) cultivars to inoculation with Azospirillum spp. of Nepalese origin. Plant Soil 151:67-76.

8. Biswas, J.C., J.K. Ladha, and F.B. Dazzo. 2000. Rhizobia inoculation improves nutrient uptake and growth of lowland rice. Soil Sci. Soc. Am. J. 64:1644-1650.

9. Campbell, C.D., S.J. Grayston, and D.J. Hirst. 1997. Use of rhizosphere carbon sources in sole carbon source tests to discriminate soil microbial communities. J. Microbiol. Methods 30:33-41.

10. Chen, Y.P., P.D. Rekha, A.B. Arun, F.T. Shen, W.A. Lai, and C.C. Young. 2006. Phosphate solubilizing from subtropical soil and their tricalcium phosphate solubilizing abilities. Appl. Soil Ecol. 34:33-41.

11. Choudhary, D.K., and B.N. Johri. 2009. Interactions of Bacillus spp. and plants-with special reference to induced systemic resistance (ISR). Microbiol. Res. 164:493-513.

12. Döbereiner, J., I.E. Marriel, and M. Nery. 1976. Ecological distribution of Spirillum lipoferum Beijerinck. Can. J. Microbiol. 22:1464-1473.

13. Elbeltagy, A., K. Nishioka, T. Sato, H. Suzuki, B. Ye, T. Hamada, T. Isawa, and H. Mitsui. 2001. Endophytic colonization and in planta nitrogen fixation by a Herbaspirillum sp. isolated from wild rice species. Appl. Environ. Microbiol. 67:5285-5293.

14. Food and Fertilizer technology Center (FFTC). 2007. Appropriate use of bio-fertilizers and bio-pesticides for small-scale farmers in Asia. Newsletter 159: Articles on Appropriate Use of Bio-Fertilizers and Biopesticides+Facing up to the Threat of Soil Pollution to Food Safety, Food and Fertilizer technology Center, Taipei.

15. Glick, B.R. 1995. The enhancement of plant growth by free living bacteria. Can. J. Microbiol. 41:109-114.

16. Glick, B.R. 2012. Plant growth-promoting bacteria: mechanisms and applications. Scientifica 2012:1-15.

17. Glickmann, E., and Y. Dessaux. 1995. A critical examination of the specificity of the Salkowski Reagent for indolic compounds produced by phytopathogenic bacteria. Appl. Environ. Microbiol. 61:793-796.

18. Grayston, S.J., S. Wang, C.D. Campbell, and A.C. Edwards. 1998 Selective influence of plant species on microbial diversity in the rhizosphere. Soil Biol. Biochem. 30:369-378.

19. Habibi, S., S. Djedidi, K. Prongjunthuek, M.F. Mortuza, N. OhkamaOhtsu, H. Sekimoto, and T. Yokoyama. 2014. Physiological and genetic characterization of rice nitrogen fixer PGPR isolated from rhizosphere soils of different crops. Plant Soil 379:51-66.

20. Hegde, S., and V. Hegde. 2013. Assessment of global rice production and export opportunity for economic development in Ethiopia. Int. J. Sci. Res. (Raipur) 2:257-260.

21. Hu, X.F., J. Chen, and J.F. Guo. 2006. Two phosphate and potassium solubilizing bacteria isolated from Tiannu mountain, Zhejiang, China. World J. Microbiol. Biotechnol. 22:983-990.

22. Jha, B.K., M.G. Pragash, J. Cletus, G. Raman, and N. Sakthivel. 2009. Simultaneous phosphate solubilization potential and antifungal activity of new fluorescent pseudomonad strains, Pseudomonas aeruginosa, $P$. plecoglossicida and P. mosselii. World J. Microbiol. Biotechnol. 25:573-581.

23. Kloepper, J.W., and M.N. Schroth. 1978. Plant growth promoting rhizobacteria on radishes, p. 879-882. Fourth International Conference on Plant Pathogenic Bacteria, Angers.
24. Kloepper, J.W., C.M. Ryu, and S. Zhang. 2004. Induced systemic resistance and promotion of plant growth by Bacillus spp. Phytopathology 94:1259-1266.

25. Kumar, P., R.C. Dubey, and D.K. Maheshwari. 2012. Bacillus strains isolated from rhizosphere showed plant growth promoting and antagonistic activity against phytopathogens. Microbiol. Res. 167:493-499.

26. Kuske, C.R., L.O. Ticknor, M.E. Miller, J.M. Dunbar, J.A. Davis, S.M Barns, and J. Belnap. 2002. Comparison of soil bacterial communities in rhizospheres of three plant species and the interspaces in an arid grassland. Appl. Environ. Microbiol. 68:1854-1863.

27. Ladha, J.K., and P.M. Reddy. 2003. Nitrogen fixation in rice systems: state of knowledge and future prospects. Plant Soil 252:151-167.

28. Lavakush, J. Yadav, J.P. Verma, D.K. Jaiswal, and A. Kumar. 2014. Evaluation of PGPR and different concentration of phosphorus level on plant growth, yield and nutrient content of rice (Oryza sativa). Ecol. Eng. 62:123-128.

29. Lupwayi, N.Z., W.A. Rice, and G.W. Clayton. 1998. Soil microbial diversity and community structure under wheat as influenced by tillage and crop rotation. Soil Biol. Biochem. 30:1733-1741.

30. Marques, A.P.G.C., C. Pires, H. Moreira, A.O.S.S. Ragel, and P.M.L. Castro. 2010. Assessment of the plant growth promotion abilities of six bacterial isolates using Zea mays as indicator plant. Soil Biol. Biochem. 42:1229-1235.

31. Meunchang, S., S. Panichsakpatana, and T. Yokoyama. 2004. Phylogenetic and physiological characterization of indigenous Azospirillum isolates in Thailand. Soil Sci. Plant Nutr. 50:413-421.

32. Mirza, M.S., W. Ahmad, F. Latif, J. Haurat, R. Bally, K.P. Normand, and A. Malik. 2001. Isolation, partial characterization, and the effect of plant growth-promoting bacteria (PGPB) on micropropagated sugarcane in vitro. Plant Soil 237:47-54

33. Mirza, M.S., S. Mehnaz, P. Normand, C. Prigent-Combaret, B.R. Moenne-Leccoz, and K.A. Malik. 2006. Molecular characterization and PCR detection of a nitrogen-fixing Pseudomonas strain promoting rice growth. Biol. Fertil. Soils 43:163-170.

34. Nadeem, S.M., M. Ahmad, Z.A. Zahir, A. Javaid, and M. Ashraf. 2013. The role of mycorrhizae and plant growth promoting rhizobacteria (PGPR) in improving crop productivity under stressful environments. Biotechnol. Adv. 32:429-448.

35. Naik, P.R., G. Raman, K.B. Narayanan, and N. Sakthivel. 2008. Assessment of genetic and functional diversity of phosphate solubilizing fluorescent pseudomonads isolated from rhizospheric soil. BMC Microbiol. 8:1-14.

36. Ohyama, T., T. Yokoyama, I. Narumi, et al. 2006. Biofertilizer Manual. Japan Atomic Industrial Forum (JAIF), Tokyo.

37. Pikovskaia, R.I. 1948. Metabolisation of phosphorus in soil in connection with vital activity of some microbial species. Microbiologiya 17:362-370.

38. Redel, Y.D., R. Rubio, J.L. Rouanet, and F. Borie. 2007. Phosphorus bioavailability affected by tillage and crop rotation on a Chilean volcanic derived Ultisol. Geoderma 139:388-396.

39. Ribeiro, C.M., and E.J. Cardoso. 2012. Isolation, selection and characterization of root-associated growth promoting bacteria in Brazil Pine (Araucaria angustifolia). Microbiol. Res. 167:69-78.

40. Saharan, B.S., and V. Nehra. 2011. Plant growth promoting rhizobacteria: A critical review. Life. Sci. Med. Sci. 21:1-30.

41. Tamura, K., G. Stecher, D. Peterson, A. Filipski, and S. Kumar. 2013. MEGA6: Molecular Evolutionary Genetics Analysis Version 6.0. Mol. Biol. Evol. 30:2725-2729.

42. Van, R.L.P. 2002. Procedures for Soil Analysis. 6th ed. International Soil Reference and Information Centre (ISRIC), Food and Agriculture Organization of the United Nations, Wageningen.

43. Yanni, Y.G., R.Y. Rizk, V. Corich, et al. 1997. Natural endophytic association between Rhizobium leguminosarum bv. trifolii and rice roots and assessment of its potential to promote rice growth. Plant Soil 194:99-114.

44. Yokoyama, T., S. Ando, T. Murakami, and H. Imai. 1996. Genetic variability of the common nod gene in soybean bradyrhizobia isolated in Thailand and Japan. Can. J. Microbiol. 42:1209-1218.

45. Zhang, C., and F. Kong. 2014. Isolation and identification of potassiumsolubilizing bacteria from tobacco rhizospheric soil and their effect on tobacco plants. Appl. Soil Ecol. 82:18-25. 